\title{
A STUDY OF THE LIFE HISTORY OF MICROPHALLUS PARAGRAPSI SMITH 1983 (TREMATODA : MICROPHALLIDAE)
}

\author{
by P. J. Bell
}

(with three tables and four text-figures)

BELL, P. J., 1988 (31:x): A study of the life history of Microphallus paragrapsi Smith 1983 (Trematoda :

Microphallidae). Pap. Proc. R. Soc. Tasm. 122(2): 119-125. https://doi.org/10.26749/rstpp.122.2.119 ISSN 0080-4703. 43 Waterloo Crescent, Battery Point, Tasmania, Australia 7000; formerly Department of Zoology, University of Tasmania.

Metacercariae of the microphallid trematode Microphallus paragrapsi Smith 1983 were found in the nervous system of the smooth pebble crab Philyra laevis (Bell 1855). Sporocysts of $M$. paragrapsi were found in the hepatopancreas of the intertidal gastropod Assiminea brazieri (Tenison Woods 1876). Under laboratory conditions, cercariae were found to emerge from the snail host and invade the intertidal crab $P$. laevis, where they subsequently encysted within the nerves innervating the legs and claws. Adults of $M$. paragrapsi were found in the gut of the Pacific gull Larus pacificus (Latham 1801). The life history of $M$. paragrapsi is very similar to the life history of the related species Microphallus pachygrapsi Deblock \& Prevot 1969.

Key Words: Microphallus paragrapsi, life-history, microphallid, crab, Tasmania.

\section{INTRODUCTION}

In 1982, during a study of parasites of the smooth pebble crab Philyra laevis (Bell 1855), metacercariae were found in the nervous system of crabs from a number of localities in Tasmania. On excystment in vitro, the metacercariae were identified as those of the microphallid Microphallus paragrapsi Smith 1983 which was first described from specimens found in the nervous system of another foreshore crab, Paragrapsus gaimardii (M. Edw.). Only one other microphallid, Microphallus pachygrapsi Deblock \& Prevot 1969, has been recorded from the nervous system of its crustacean intermediate host.

Since there is a paucity of information on the biology of $\mathbf{M}$. paragrapsi an investigation of the life history was undertaken and is the subject of this paper.

\section{METHODS AND MATERIALS}

Crabs Philyra laevis were collected from Great Bay and Barnes Bay, Bruny Island, and Pipe Clay Lagoon in southeastern Tasmania. They were maintained in the laboratory for up to one week prior to dissection and examination. A record was made of the degree and incidence of infection with cysts of $M$. paragrapsi.

Crabs collected from Barnes Bay were found to be suitable for experimental infection as the incidence of infection appeared to be very low. Of
200 crabs examined throughout the study period, none were infected by $M$. paragrapsi and only one crab was found to be infected with a single cyst of the trematode Maritrema eroliae Yamaguti 1939.

Metacercarial cysts were dissected free of host tissue, rinsed and stored at $5^{\circ} \mathrm{C}$ in Hank's Balanced Salt Solution (Hank's BSS) for up to one week prior to excystment procedures. The technique and solution sequences used for excystment followed those given by Smith (1983) for the excystment of $M$. paragrapsi.

Fourteen species of mollusc were collected from Great Bay at monthly intervals between March and September 1982, and nine species from Pipe Clay Lagoon at irregular intervals during the same year (table 1). Snails were maintained in the laboratory and monitored for release of cercariae. Those found to be releasing xiphidocercariae were maintained in isolation with crabs (considered to be free from infection) collected from Barnes Bay, Bruny Island. These crabs were subsequently dissected and examined for cysts of $M$. paragrapsi. By this process, the minute intertidal gastropod Assiminea brazieri (Tenison Woods 1876) was implicated as a primary host for $M$. paragrapsi.

Newly emerged cercariae were collected from vials containing $A$. brazieri in filtered sea water. This material was used for description of cercariae, experimental infection of crabs and observations on behaviour. Additional material was collected from freshly dissected snails. Crabs experimentally infected with cercariae were maintained at $30^{\circ} \mathrm{C}$ in filtered sea water until dissection. 
Several species of birds were found to frequent Great Bay and Pipe Clay Lagoon, including the pied oyster catcher, silver gull and Pacific gull. In the summer of $1981 / 82$ G. Coulson (pers. comm.) identified crabs $P$. laevis and $P$. gaimartii, from regurgitated peliets of the Pacific gull, on Green Island, in southeastern Tasmania. This evidence implicated the Pacific gull as a defin itive host for $M$. paragrapsi. In October 1982, after obtaining a permit from the Tasmanian National Parks and Wildlife Service, two Pacific gulls (1 male, 1 female) were shot at Pipe Clay Lagoon. Dissection was carried out within a few hours of death. The oesophagus, crop, gizzard, liver and pancreas were removed and examined for the presence of adults of $M$. paragrapsi. The intestine (gizzard to anus) was cut into twelve equal lengths and each was examined separately for adult worms.

Examination of live material was facilitated by placing worms on a slide under slight coverslip pressure and when necessary, worms were immobilised by warming the slide. Aqueous vital stain solutions, brilliant cresyl blue and neutral red, were used to observe glands and ducts. All observations were made using a dissecting microscope and a Carl Zeiss compound microscope. The measurements of adult worms, metacercariae, excysted metacercariae, sporocysts and other larval worms are based on specimens fixed in $10 \%$ phosphate-buffered formol saline, under coverslip pressure. Measurements are given in microns, the mean first, followed by the range in brackets.

\section{RESULTS}

Life History

Sporocysts were found on the hepatopancreas of the gastropod Assiminea brazieri. As many as 100 sporocysts were dissected from the host tissue of a single snail. In October, one of 200 snails collected from Great Bay and eight of 100 snails collected from Pipe Clay Lagoon were found to be infected.

Under laboratory conditions, cercariae were observed to emerge from the snail host and continue swimming until exhausted or contacting the gill surface of the crab Philyra laevis. By the respiratory current, cercariae were drawn into the branchial chamber of the crab. On contaet with the gill surface the tail was discarded and cercariae crawled between adjacent gill lamellae and penetrated the branchial vein.

Crabs, that had been experimentally exposed to cercariae and dissected after 30 minutes, had tailless cercariae between gill lamellae and postcercariae within the branchial vein. After 18 hours (fig. 1B), several post-cercariae were found in the haemocoels. After 4 days (fig. 1C) immature cysts were present in the major nerves innervating the

TABLE 1

Molluscs Examined for Larval Trematodes

\begin{tabular}{lcc} 
Species & \multicolumn{2}{c}{ Number of individuals examined } \\
\cline { 2 - 3 } & Great Bay & Pipe Clay Lagoon \\
\hline Zeacumantus diemenensis & 400 & 400 \\
Parcanassa pauperata & 1200 & 1800 \\
Melarapha unifasciata & 300 & \\
M. praetermissa & 40 & \\
Austrocochlea constricta & 300 & 200 \\
A. concamerata & 50 & \\
Lepsiella vinosa & 200 & 25 \\
Cominella lineolata & 120 & 400 \\
Salinator fragilis & 200 & 250 \\
Bembicium auratum & 300 & 200 \\
Assiminea brazieri & 200 & 300 \\
Anepella cycladaa & 100 & 100 \\
Katelysia scalarina & & \\
Mytilus planulatus & 30 &
\end{tabular}


legs. Cyst diameter measured about $250 \mu \mathrm{m}$. The cyst wall was extremely fine and single layered. The penetration glands and the oral sucker were indiscernible. The tegumental spines were prominent and the excretory bladder had increased in size. After 14 days (fig. 1D), cyst diameter measured about $295 \mu \mathrm{m}$. The cyst wall was two layered, the outer layer radially striated. The oral sucker was well developed, the ventral sucker was partially developed, though small in diameter, and the excretory vesicle was large and well developed.

Although metacercarial cysts usually were found in the major nerves innervating the legs and the claws of the crab P. laevis, cysts were found less frequently in the abdominal nerve or one of the major nerves leading to the cephalic appendages. Of 264 crabs (112 female, 152 male), collected from Great Bay between March and September, 233 were found to be infected with metacercarial cysts. The mean degree of infection was 11 (range 1-102) cysts per crab (all of ten crabs collected from Pipe Clay Lagoon were infected, with a mean of 53 cysts per crab). A peak of 18 cysts per crab (mean number of cysts per crab in a sample of 50 crabs) of Philyra laevis at Great Bay occurred in June. This corresponded with a peak in the incidence of infection $(96 \%)$ and the highest mean percentage of immature cysts present per crab $(43 \%)$.

Ovigerous adult worms $M$. paragrapsi were found in the posterior half of the intestine of the Pacific gull Larus pacificus (fig. 2). Both of the birds examined were found to be infected; one bird contained 550 adult worms of $M$. paragrapsi.

\section{Descriptions}

\section{Sporocyst (fig. 3C)}

Mature sporocysts are elongate and contain up to about 8 cercariae; mean 5 (range 2-8). Small less mature sporocysts are oval in shape. Ten elongated fairly mature sporocysts measured $579 \mu \mathrm{m}(350-850)$ by $193 \mu \mathrm{m}(120-250)$.

\section{Cercaria (figs 3A, 3B)}

The cercaria is a small monostome xiphidiocercaria, characteristic of the family Microphallidae. The body and tail are highly contractile. Minute tegumental spines cover the body which measures $268 \mu \mathrm{m}(260-288)$ by $65 \mu \mathrm{m}$ $(60-78)$. An aspinose tail joins the body at the
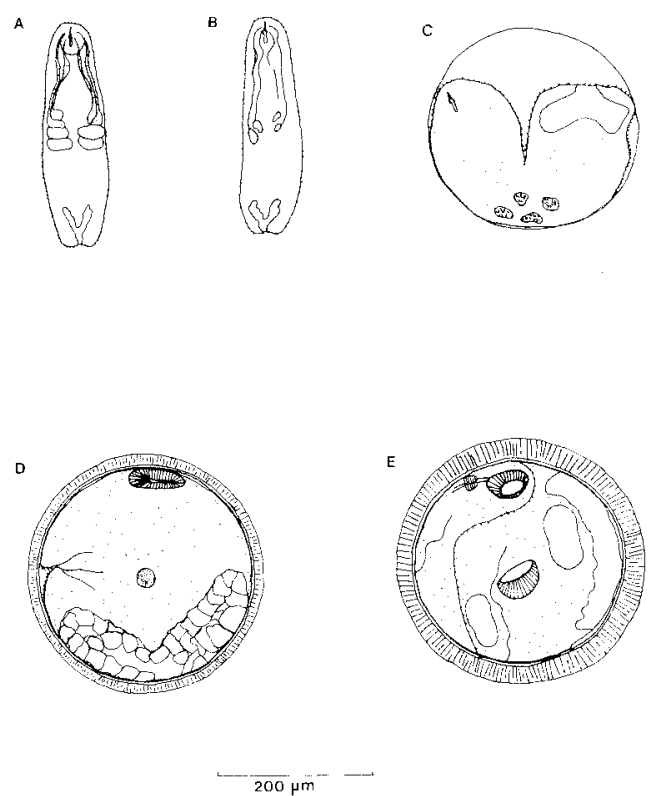

FIG. I - Microphallus paragrapsi. Growth and development in the crab host Philyra laevis. (A) after 1 hour at room temperature; $(B)$ after 18 hours at $30^{\circ} \mathrm{C} ;(\mathrm{C})$ after 4 days at $30^{\circ} \mathrm{C} ;(D)$ after 14 days at $30^{\circ} \mathrm{C} ;($ E) mature metacercarial cyst.

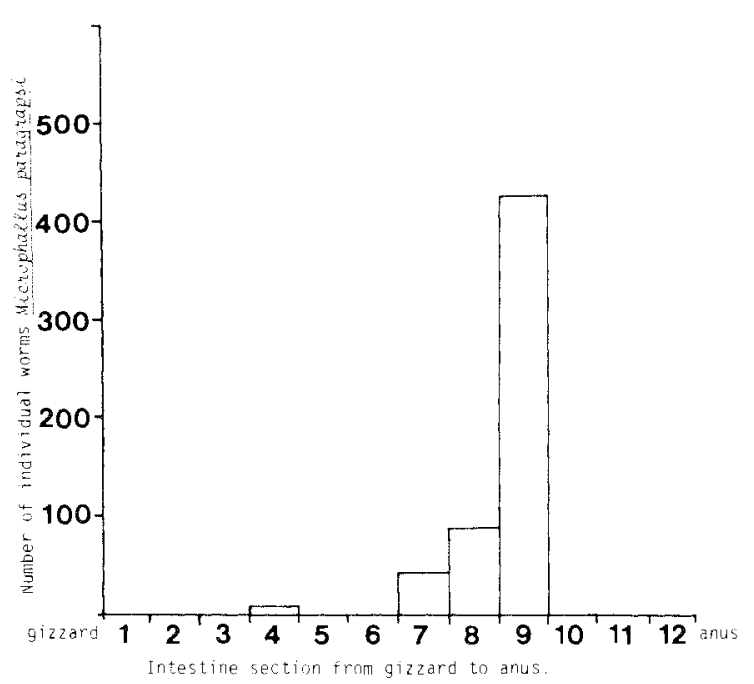

FlG, 2 - Site of infection of Microphallus paragrapsi in the Pacific gull Larus pacificus. 

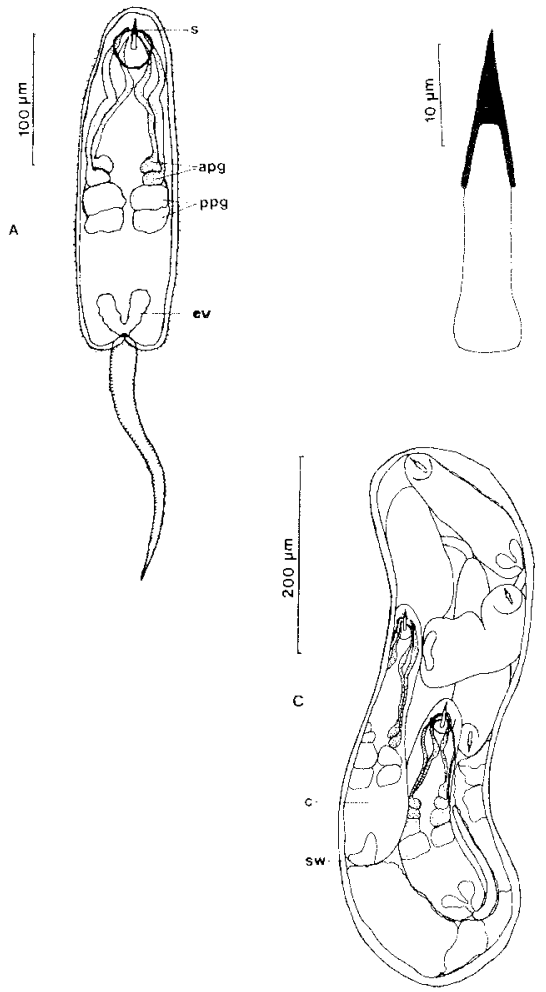

FIG. 3 - Microphallus paragrapsi. (A) cercaria; (B) dorsal view of stylet; (C) sporocyst (apg $=$ anterior penetration glands, $c=$ cercaria, $e v=$ excretory vesicie, $o s=$ oral sucker, $p p g=$ posterior penetration glands, $s w=$ sporocyst wall, $s=$ stylet $)$.

posterior socket and gradually tapers towards its tip. Tegumental annulations occur along its length. The tail has a length of $170 \mu \mathrm{m}(163-185)$ and an anterior width of $12 \mu \mathrm{m}$ (10-15). A large stylet (fig. 3B) is embedded in the dorsal anterior portion of the oral sucker. The anterior one-fifth of the stylet is entirely thickened, the remainder as far as the basal one-eighth is only partially thickened. The stylet measures: length $29 \mu \mathrm{m}$ (26-31), stylet point $19 \mu \mathrm{m}(18-20)$ and the stylet base $6 \mu \mathrm{m}(5-7.5)$. The oral sucker measures $35 \mu \mathrm{m}$ (32-37) by $32 \mu \mathrm{m}$ (30-35). Four pairs of unicellular penetration glands with long sigmoidal ducts, open anteriorly at the level of the stylet, about half way along its length. The two posterior pairs are larger. The excretory bladder is large, bilobed and conspicuous when dilated. Details of the excretory ducts and flame cells were not determined.
A
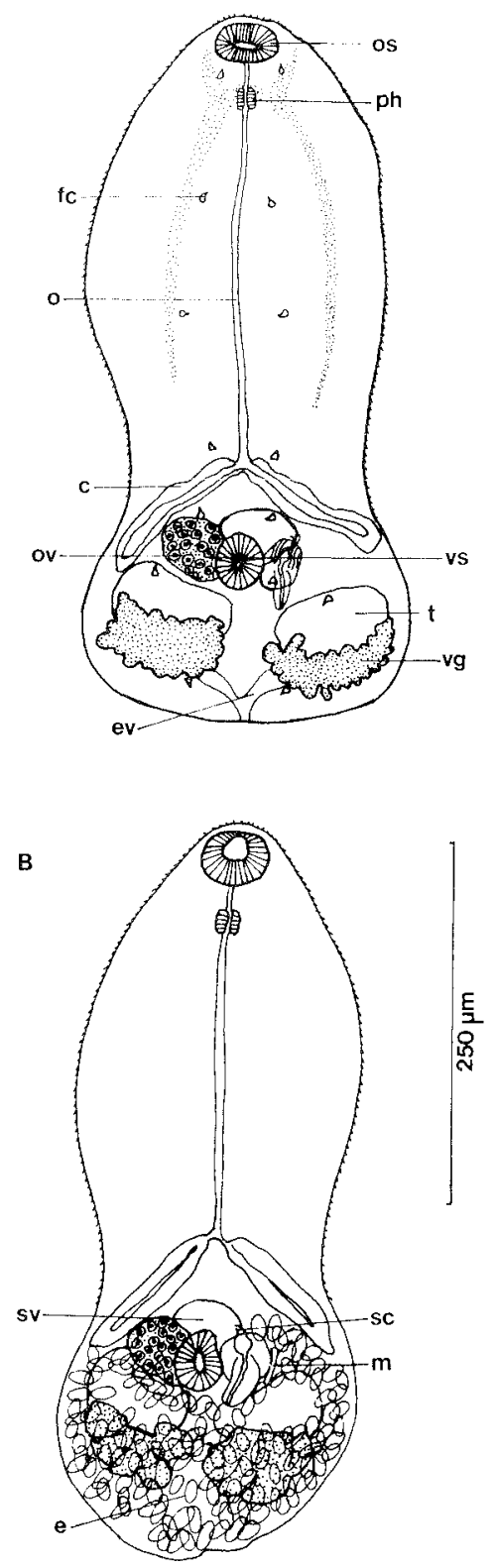

FIG. 4 - Microphallus paragrapsi. (A) excysted metacercariae from Philyra laevis; $(B)$ gravid adult from the gut of Larus pacificus $(c=$ cercaria, $e=e g g, e v=$ excretory vesicle, $f_{c}=$ flame cell, $m=$ metrater $m, m m p=$ male papilla, $o=$ ovary, $o s=$ oral sucker, $p h=$ pharynx, $s c=$ seminal canal , $s v=$ seminal vesicle, $t=$ testis, $v g=$ vitellaria, $v s=$ ventral sucker). 


\section{Metacercaria (figs 1E, 4A)}

Mature cysts are round and measure $313 \mu \mathrm{m}$ $(270-353)$ in diameter. The cyst wall thickness is $48 \mu \mathrm{m}(30-60)$. Metacercarial cysts removed from the nervous system of $P$. laevis and excysted in vitro, are dimensionally and morphologically consistent with the description of $M$. paragrapsi by Smith (1983). The dimensions of worms excysted and flattened under coverslip pressure are presented in table 2 . The flame cell formula was tentatively determined to be $2[(2+2)+(2+2)]=16$.

\section{Adult (fig. 4b)}

Adult worms removed from the gut of $L$. pacificus are morphologically and dimensionally consistent with the description of $M$. paragrapsi by Smith (1983). Features used to make the determination are: body shape pyriform to elongate spatulate with distinct waist anterior to seminal vesicle; tegumental spines quincuncially arranged, diminishing in size posterior, extending to waist level; tegumental gland cells distributed over anterior body; oral sucker transversely oval to round, mouth subterminal ventral; prepharynx short; oesophageal bifurcation in posterior half of body; caeca relatively short, terminating at midlevel of ventral sucker; ventral sucker round, smaller than oral sucker; testis oval, equal posterolateral; no cirrus pouch, seminal vesicle oval, partly dorsal to ventral sucker; seminal canal leading posteriorly from seminal vesicle to expanded pars prostatica at base of male papilla; prostrate gland cells located between seminal vesicle and male papilla, clustered around seminal canal; everted male papilla tubular, directed posteromedially; ovary oval, contiguous to dextral caecum and testis, dextral and partly dorsal to ventral sucker; vitelline gland cells clustered in compact bunches posterior to each testis; eggs numerous and oval; and excretory vesicle V-shaped, limbs extending to testes. The dimensions of ovigerous worms and a nonovigerous worm are presented in table 3 .

\section{DISCUSSION}

Cysts removed from the nervous system and experimentally excysted metacercariae from Philyra laevis are dimensionally and morphologically consistent with the description of Microphallus paragrapsi Smith 1983. The location of cysts in $P$. laevis is identical to that recorded by

TABLE 2 Microphallus paragrapsi metacercariae

\section{Dimension* $(\mu \mathrm{m})$}

\begin{tabular}{lrl}
\hline Body length & 502 & $(300-750)$ \\
Body width & 125 & $(13-168)$ \\
& & \\
Oral sucker length & 55 & $(30-68)$ \\
Oral sucker wiodth & 60 & $(34-79)$ \\
Prepharynx length & 12 & $(6-26)$ \\
Oesophagus length & 280 & $(188-335)$ \\
Ovary width & 33 & $(15-56)$ \\
Pharynx length & 26 & $(15-34)$ \\
Pharynx width & 26 & $(15-34)$ \\
Left carcum length & 185 & $(131-262)$ \\
Right carcum length & 173 & $(113-262)$ \\
Ventral sucker length & 58 & $(38-64)$ \\
Right testis width & 63 & $(53-75)$ \\
Ventral sucker width & 55 & $(38-60)$ \\
Seminal vesicle width & 36 & $(19-51)$ \\
Seminal vesicle length & 55 & $(30-78)$ \\
Ovary length & 53 & $(26-82)$ \\
Left testis length & 70 & $(56-94)$ \\
Left testis width & 65 & $(48-94)$ \\
Right testis length & 72 & $(52-105)$ \\
& & \\
& &
\end{tabular}

* Metacercariae, flattened under coverslip pressure, 2 hours after excystment $(n=10)$.

Smith (1983) from the host Paragrapsus gaimardii. Furthermore the distributions of Philyra laevis and Paragrapsus gaimardii, at Great Bay and Pipe Clay Lagoon overlap and both species naturally occur in close proximity to the snail Assiminea brazieri. $M$. paragrapsi from the nerves of $P$. gaimardii and cysts found in the nerves of Philyra laevis are therefore considered to the the same species. Mature ovigerous worms removed from the gut of the Pacific gull are morphologically and dimensionally consistent with the description of $M$. paragrapsi and are likewise considered to be the same species.

According to Smith (1981) the only other microphallid known to encyst in the nerves of its crustacean intermediate host is Microphallus pachygrapsi, a parasite in the crab Pachygrapsus marmoratus, on the Mediterranean coast of France. The life history of $M$. pachygrapsi has been described (Prevot 1971, 1974), particularly the mode of penetration and subsequent finding of the encystment site. Penetration by $M$. pachygrapsi occurs through the gills of its crab host and 
TABLE 3

Microphallus paragrapsi from the Gut of the Pacific Gull Larus pacificus

\begin{tabular}{lrlr} 
Dimension* & \multicolumn{2}{c}{$\begin{array}{c}\text { Ovigerous adults } \\
(\boldsymbol{\mu} \mathbf{m})\end{array}$} & $\begin{array}{c}\text { Non-ovigerous adult } \\
(\boldsymbol{\mu} \mathbf{m})\end{array}$ \\
\hline Body length & 513 & $(450-560)$ & 460 \\
Body width & 186 & $(175-200)$ & 193 \\
Oral sucker length & 43 & $(40-50)$ & 43 \\
Oral sucker width & 46 & $(43-50)$ & 46 \\
Prepharynx length & 19 & $(7.5-35)$ & 22 \\
Oesophagus length & 195 & $(158-210)$ & 179 \\
Pharynx length & 25 & $(20-28)$ & 23 \\
Pharynx length & 23 & $(20-25)$ & 22 \\
Left caecum length & 112 & $(103-120)$ & 98 \\
Right caecum length & 105 & $(100-112)$ & 100 \\
Ventral sucker length & 40 & $(28-45)$ & 38 \\
Ventral sucker width & 35 & $(33-43)$ & 36 \\
Seminal vesicle length & 44 & $(38-50)$ & 40 \\
Seminal vesicle width & 35 & $(30-50)$ & 30 \\
Ovary length & 45 & $(35-60)$ & 40 \\
Ovary width & 41 & $(35-43)$ & 35 \\
& & & 1 \\
Sample size & 7 & & \\
\hline
\end{tabular}

* Specimens fixed, under coverslip pressure.

encystment takes place within the nerves of the legs and claws. The cercariae travel by way of the circulatory system. Some cercariae are carried by the stemal artery into the limb arteries. At the junction between the basipodite and ischiopodite of the periopods, the appendiculate nerve branches and passes close to the blood capillaries. At this point cercariae penetrate the nerve and ascend to variable sites. Cercariae travelling by other arteries may relocate by migration through the sinuses. As the site of external penetration and encystment site of both $M$. paragrapsi and $M$, pachygrapsi are identical and the species are closely related, it is likely the mode of site-finding in both species is similar. This would account for the presence of post-cercariae in the body cavity of Philyra laevis during experimental infection.

Encystment of $M$. paragrapsi occurred within four days at $30^{\circ} \mathrm{C}$. High temperatures may be recorded in rock pools but this is unlikely to be a continuous environmental temperature for crabs. Generally, the development rate of larval trematodes increases with increase in temperature, so under natural conditions it is expected that postcercariae take longer than four days to encyst.
Prevot (1974) found $M$. pachygrapsi took a variable length of time to encyst, ranging between one and seven days.

Results from the survey of crabs at Great Bay suggest a seasonal component to infection by $M$. paragrapsi. A peak in the degree of infection (mean number of cysts per crab) occurred in June, as did the percentage of immature cysts per crab. Seasonal variations in infection have been recorded for many crustacean hosts (Yamaguti 1975) and for molluscan and vertebrate hosts (Smith 1971, Bakke 1972). A variation in feeding habits and/or frequency of occurrence of the vertebrate host at study sites may be sufficient to produce subsequent variation in the infection levels of the primary and intermediate hosts. Pacific gulls are found only in southern Australia and do not undertake seasonal migrations (Tuck \& Heinzel 1980), therefore any seasonal variation in occurrence at study sites must be on a local scale.

Sufficient information is available to speculate on the geographical distribution of the developmental stages of $M$. paragrapsi. Trematodes show a high degree of host specificity at the primary-host level and individual species of 
trematodes tend to be restricted to molluscan species of a single genus (Erasmus 1972, Ewers 1964). If $M$. paragrapsi is species-specific at the molluscan host level, then its distribution would be confined to southern Australian waters, the known distribution of A brazieri.

The life history of $M$. paragrapsi can be postulated from the results of this study. The life history involves a three-host cycle: molluscan primary host, Assiminea brazieri; crustacean intermediate hosts, Philyra laevis and Paragrapsus gaimardii; and the final vertebrate host Larus pacificus. Adult worms infect the posterior gut of the Pacific gull. When eggs are shed they pass out in the bird's faeces. Infection of the snail host will result from ingestion of the egg by a browsing snail and subsequent hatching of the egg containing a miracidium. Development and multiplication take place in the hepatopancreas of the snail. Cercariae develop within sporocysts; mature cercariae emerge from the snail host and have a brief life-span swimming freely in the sea. By chance cercariae may be drawn into the branchial chamber of the crab host. On contact with the gill surface the cercariae penetrate the crab and subsequently encyst within the nervous system. When the infected crab is ingested by a Pacific gull, metacercariae excyst and become sexually mature in the posterior gut of the bird, thus completing the life history.

\section{ACKNOWLEDGEMENTS}

This work was conducted as part of an Honours project at the Zoology Department, University of Tasmania. Thanks are due to the Department staff and in particular Dr John L. Hickman, who supervised this study and gave advice on preparation of the manuscript. Acknowledgement is also due to Graeme Coulson (University of Melbourne) for providing feeding information on Pacific gulls and the Tasmanian National Parks and Wildlife Service for a permit.

\section{REFERENCES}

BAKKE, T.A., 1972: Studies on the helminth fauna of Norway XXII. The common gull, Larus canus L., as final host for Digenea (Platyhelminthes). Norw. J. Zool. 20: 165-188.

ERASMUS, D.A., 1972: THE BIOLOGY OF TREMATODES. Edward Amold (Pub.) Limited, London.

EWERS, W.H., 1964: An analysis of the molluscan hosts of the trematodes of birds and mammals and some speculation on host specificity. Parasitology 54: 571-578.

PREVOT, G., 1971: Contribution a l'étude des Microphallidae Travassos, 1920 (Trematoda). Cycle évolutif de Microphallus pachygrapsi Deblock et Prevot, 1969 parasite du Goé land a pieds jaunes (Larus argentatus). Ann. Parasitol. (Paris) 46: 453-461.

PREVOT, G., 1974: Recherches sur le cycle biologique et l'écologie de quelques trematodes nouveaux parasites de Larus argentatus Machaellis naumann dans le midi de la France. Unpubl. D. es-Sc. thesis, Univ. de Droit, d'Economie et des Sciences d'Aix-Marseille.

SMITH S.J., 1971: A study of some larval digenetic trematodes infecting invertebrates in Calvert's Lagoon, Unpubl. B.Sc. Hons. thesis, Univ. Tasm.

SMITH, S.J., 1981: The trematode fauna of a brackish lagoon in Tasmania. Unpubl. Ph.D. thesis, Univ. Tasm.

SMITH, S.J., 1983: Three new species and a new record of microphallid trematodes from Tasmania, with observations on their in vitro development. Pap. Proc. R. Soc. Tasm. 117: 105-123.

TUCK, G.S. \& HEINZEL, H., 1980: A FIELD GUIDE TO THE SEABIRDS OF AUSTRALIA AND THE WORLD. Collins, Sydney.

YAMAGUTI, S, 1975: A SYNOPTIC REVIEW OF LIFE HISTORIES OF DIGENETIC TREMATODES IN VERTEBRATES. Keigaku Publishing Company, Tokyo.

(accepted 13 June 1988) 